\title{
Three-Dimensional Printing in Medicine: Current Status and Future Perspectives
}

\author{
Emil Mammadov $(1)$ \\ Department of Pediatric Surgery, Near East University School of Medicine, Nicosia, Cyprus
}

ORCID ID of the author: E.M. 0000-000I-8143-1643.

Cite this article as: Mammadov E. Three-Dimensional Printing in Medicine: Current Status and Future Perspectives. Cyprus J Med Sci 2018; 3(3): 186-8.

\begin{abstract}
Three-dimensional (3D) printing has emerged as a defining component of the medical research and manufacturing industry in the past 10 years. The main applications of 3D printing in medicine are the development of educational and simulation models, patient-specific surgical guides and implants, and rapid prototyping of medical devices and biofabrication. 3D printing for preoperative planning in orthopedic, maxillofacial, spinal, cardiac, and oncologic surgery is currently the most prominent topic in published literature. At the same time, the models acquired via medical imaging may be used for 3D print custom implants tailored to patient's needs. Yet, the most promising field where 3D printing is being used in medicine is biofabrication of cell and tissue constructs, and this technology will possibly change the whole approach both to organ transplantation and drug research in the near future. 3D printing is expected to have a huge impact on the future of medicine. Current hype emerging from simple curiosity is steadily transitioning to a more structured approach through unbiased scientific research.
\end{abstract}

Keywords: 3D printing, medicine, future

\section{INTRODUCTION}

The production of solid objects by adding them layer by layer is called additive manufacturing. This term was popularized in the early 2000s and evolved to a more popular one called "3D printing", which describes the processes used in additive manufacturing. Initial 3D printers were developed in the 1980s but the real hype started in the late 1990 s after commercial $3 \mathrm{D}$ printers were introduced to the masses. The real popularity was achieved through the community, which called themselves "the makers". These enthusiasts used common designs and introduced them to the public via open source codes. With the development of social media, video streaming, and online 3D printer spare parts shopping, kits with online assembly instructions have become available to common users, which has led to great reduction of the printer prices. The health sector rapidly integrated 3D printing in its workflow and 3D printing became one of the locomotives of the industry. In this article, we will describe the process of 3D printing, the technologies used, their applications, and current status in medicine.

\section{How Is It Done?}

All processes start with a 3D model acquired via a computer-aided design, 3D scanner, photogrammetry or medical imaging software. Prior to printing, the model should be examined for errors, because 3D printers do not recognize holes, faces, self-intersections, and manifold errors. This issue is particularly encountered in models acquired by 3D scanning. After this "digital cleaning and preparation", the 3D file is processed by software called slicer which turns the model into thin layers and produces a code that is recognized by a 3D printer.

This code is called G-code and contains a series of coordinates and commands specific to the machine. Until this part, the process is much the same for all manufacturers. The real difference starts with the method used for 3D printing, and there are approximately 20 different technologies. The most common ones are fused deposition modeling, stereolithography, selective laser sintering, and material jetting. Fused deposition modeling (FDM) describes the process of adding layers of molten thermoplastic on each other through a moving extrusion hot end onto a bed. This is the process most frequently adopted by makers worldwide because of the ease of use and wide availability of cheap machines and supply materials. 
Stereolithography (SLA) is the process where, instead of melting, an ultraviolet (UV) curable resin is polymerized by high precision lasers in a tank. This technique produces the most precise models and is widely adopted in the field of dentistry. Selective laser sintering (SLS) uses laser to cure the powder polymer layer by layer. This method produces sophisticated durable parts mainly for engineering purposes. Material jetting is a process which uses powder, which is sprayed layer by layer with immediate curing via laser or a heat source. The last two technologies need full-time technical support, are more industrial in nature,

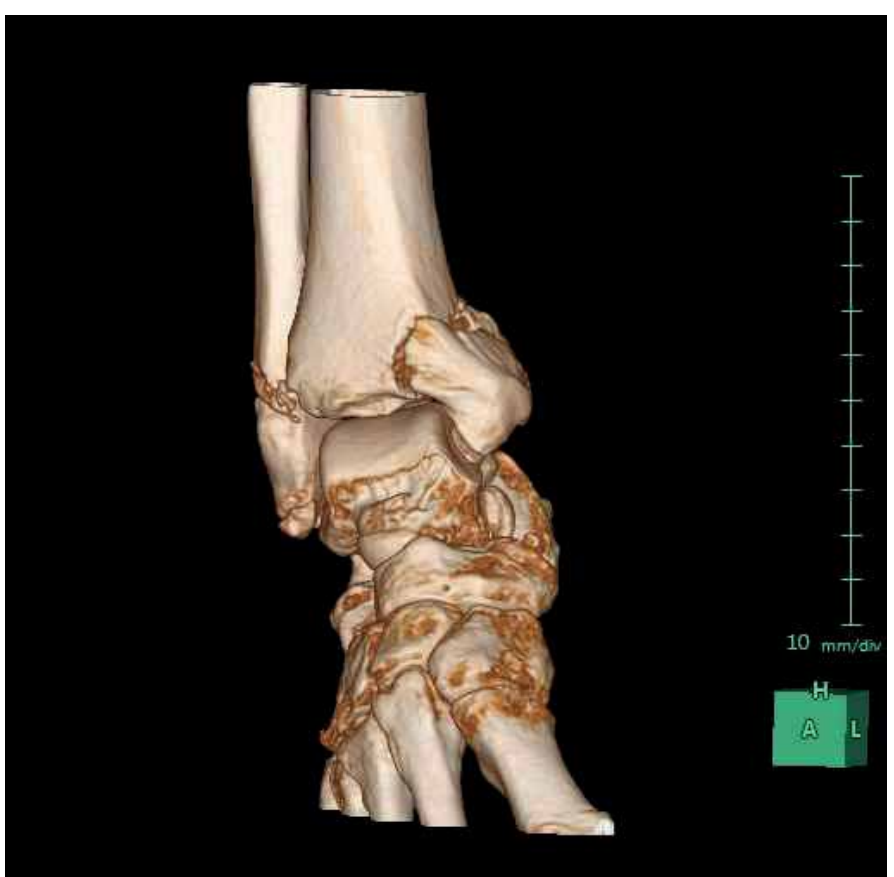

FIGURE I. Image segmentation of tibial fracture

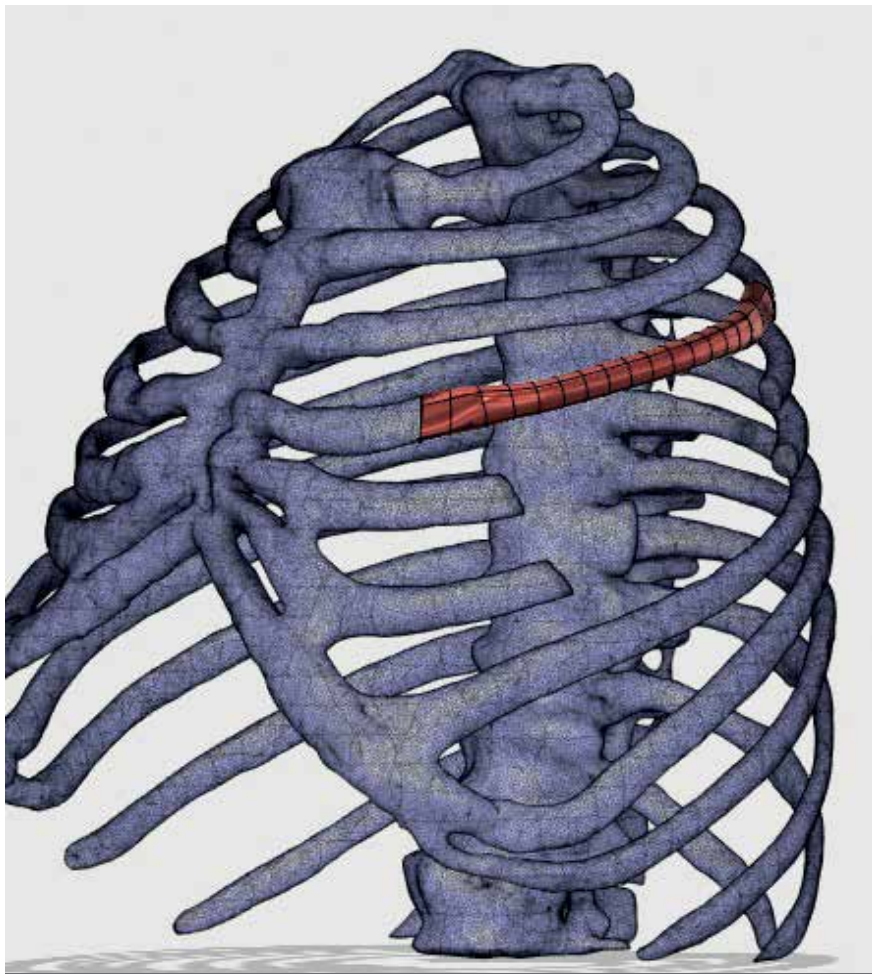

FIGURE 2. Patient-specific rib implant modeling and the machines are not affordable for ordinary users. More recently, the term "metal 3D printing" was introduced to the industry and has already been used for the production of custom surgical guides and implants. This technology is based on layer-by-layer laser or heat fusion of metal powder.

All these technologies have different resolutions, printing times, and price per part and use different materials with variable strength properties. For example, an SLA print offers a highly detailed model with a high price per part but with moderate strength and is mostly suitable for printing 3D models prior to dental and vascular procedures. SLS print is strong and detailed because it is mostly printed with polyamide; however, it requires a powder cleaning station and is more expensive than FDM and SLA prints. FDM printed model is cheaper and stronger than SLA printed model; however, it offers lower print detail and often requires printing of separate removable support structures besides the print itself. Therefore, the knowledge of these technologies is crucial before deciding to acquire a particular machine for research purposes.

\section{CURRENT APPLICATIONS IN MEDICINE}

\section{Surgical Planning and Education}

3D printing for preoperative planning in orthopedic, maxillofacial, spinal, cardiac, and oncologic surgery is currently the most prominent topic in published literature. Modern medical imaging workstations offer the possibility of converting patient images into 3D models. This process is also possible by uploading the DICOM images into freely available open source imaging software options. The software allows segmentation of the image, which means selecting the region of interest in slices and converting it to a solid 3D object (Figure I). This object is further transferred to the mesh software for digital cleanup and preparation for printing. This method allows the surgeons to prepare for surgery and reduce intraoperative decision time, particularly in complicated cases. Sodian et al (I) showed that 3D printed stereolithographic replicas were extremely useful in planning reoperations for previous coronary bypass surgery. At the same time, this method also allows the surgeon to manufacture patient- and lesion-specific guides for orthopedic, spinal, and maxillofacial surgeries (2-7). Printed models may also aid the patient to understand the planned surgical procedure better, and, at the same time, the models may be reserved for both student and resident training. However, current literature lacks randomized controlled studies to prove the proposed positive effects of 3D printing on surgical planning. We may see studies on these aspects after the current hype slows down leaving space for unbiased research.

\section{Patient-Specific Implants}

This is perhaps the most promising aspect of 3D printing in the field of surgery. The images obtained from patients allow the surgeon to plan the surgery with a 3D printed model. At the same time, this image may be reconstructed, and an implant tailored for the specific needs of the particular patient may be modeled with the dedicated software (Figure 2). This approach is already being practiced by several centers and commercial companies, and patient-specific implants are being manufactured using 3D printing $(8,9)$. In a case documented by Phan et al $(10)$, 3D printed spinal implant reduced the overall surgery time and risk of neurovascular compromise in a patient with $\mathrm{Cl} / \mathrm{C} 2$ fusion. Unfortunate- 
ly, research in this area mostly comprises case reports and case series for the treatment of specific pathologies.

\section{Bioprinting}

The most promising application of 3D printing is in the field of biofabrication. The term bioprinting refers to the process of layer-by-layer deposition of live cells suspended in a biocompatible hydrogel or via the spheroid formation. The deposition is achieved through extrusion or jetting based techniques (II). The polymers used for bioprinting are natural, such as gelatin, alginate, collagen, fibrin, or synthetic, such as polyethylene glycol, polycaprolactone (PCL), and polylactide co glycolide (PLGA) (I2). Current research is mainly focused on the development of deposition systems and polymers to provide the most suitable environment for long-term survival of cells in vitro. However, the main challenge is the inability to fully mimic the natural extracellular matrix and provide exact cell to cell signaling and interactions. Therefore, this process is extremely complex and requires a high level of expertise, both in the field of engineering and polymer and cell sciences. Printed cell aggregates are further matured in bioreactors to form a functional tissue construct. With the current pace of research in this field (|3-2|), it is possible to foresee 3D printed tissue and organs in future.

\section{Future Perspectives}

Three-dimensional printing is definitely a niche area in medicine. The most striking future perspective is definitely in the area of 3D bioprinting. Currently, budget 3D bioprinters capable of performing basic tasks are becoming widely available due to reduced prices. At the same time, many centers are building their own printers for research purposes. Even the current status of research predicts 3D printed organ and tissue constructs in the near future.

Another definite surge is expected in the field of production of patient-specific implants and prostheses. Many companies are presenting their implants printed with different materials, including titanium, and this approach will possibly be a surgical routine in the near future.

Other fields like 3D printed surgical instruments and guides and educational models are highly dependent on the mass availability of affordable 3D printers in every hospital and university.

\section{CONCLUSION}

Three-dimensional printing is expected to have a huge impact on the future of medicine. Current hype emerging from simple curiosity is steadily transforming to a more structured approach via unbiased scientific research.

Peer-review: Externally peer-reviewed.

Conflict of Interest: The author have no conflicts of interest to declare.

Financial Disclosure: The author declared that this study has received no financial support.

\section{REFERENCES}

I. Sodian R, Schmauss D, Markert M, Weber S, Nikolaou K, Haeberle S, et al. Three-dimensional printing creates models for surgical planning of aortic valve replacement after previous coronary bypass grafting. Ann Thorac Surg 2008; 85: 2105-8. [CrossRef]
2. Yun PY. The application of three-dimensional printing techniques in the fi eld of oral and maxillofacial surgery. J Korean Assoc Oral Maxillofac Surg 2015; 4I: 169-70. [CrossRef]

3. Liu $A$, Xue GH, Sun M, Shao HF, Ma CY, Gao Q, et al. 3D Printing Surgical Implants at the clinic: A Experimental Study on Anterior Cruciate Ligament Reconstruction. Sci Rep 2016; 6: 21704. [CrossRef]

4. Kamali P, Dean D, Skoracki R, Koolen PG, Paul MA, Ibrahim AM, et al. The Current Role of Three-Dimensional Printing in Plastic Surgery. Plast Reconstr Surg 2016; 137: 1045-55. [CrossRef]

5. Gerstle TL, Ibrahim AM, Kim PS, Lee BT, Lin SJ. A plastic surgery application in evolution: three-dimensional printing. Plast Reconstr Surg 2014; 133: 446-51. [CrossRef]

6. Bellanova L, Paul L, Docquier PL. Surgical guides (patient-specific instruments) for pediatric tibial bone sarcoma resection and allograft reconstruction. Sarcoma 2013; 2013: 787653. [CrossRef]

7. Wanibuchi M, Noshiro S, Sugino T, Akiyama Y, Mikami T, lihoshi S, et al. Training for skull base surgery by using a colored temporal bone model created by three-dimensional printing technology. World Neurosurg 2016; 91: 66-72. [CrossRef]

8. Chen $X, X u L$, Wang $Y$, Hao $Y$, Wang L. Image-guided installation of 3D-printed patient-specific implant and its application in pelvic tumor resection and reconstruction surgery. Comput Methods Programs Biomed 2016; 125: 66-78. [CrossRef]

9. Kim D, Lim JY, Shim KW, Han JW, Yi S, Yoon DH, et al. Sacral Reconstruction with a 3D-Printed Implant after Hemisacrectomy in a Patient with Sacral Osteosarcoma: I-Year Follow-Up Result. Yonsei Med J 2017; 58: 453-7. [CrossRef]

10. Phan K, Sgro A, Maharaj MM, D’Urso P, Mobbs RJ. Application of a 3D custom printed patient specific spinal implant for $\mathrm{Cl} / 2$ arthrodesis. J Spine Surg 2016; 2: 314-8. [CrossRef]

II. Seol YJ, Kang HW, Lee SJ, Atala A, Yoo JJ. Bioprinting technology and its applications. Eur J Cardiothorac Surg 2014; 46: 342-8. [CrossRef]

12. Carrow JK, Kerativitayanan P, Jaiswal MK, Lokhande G, Gaharwar AK. Polymers for Bioprinting. In: Atala A, Yoo JJ, editors. Massachusetts: Academic Press; 2015. p. 229-48. [CrossRef]

13. Daly AC, Cunniffe GM, Sathy BN, Jeon O, Alsberg E, Kelly DJ. 3D Bioprinting of Developmentally Inspired Templates for Whole Bone Organ Engineering. Adv Healthc Mater 2016; 5: 2353-62. [CrossRef]

14. Kang HW, Lee SJ, Ko IK, Kengla C, Yoo JJ, Atala A. A 3D bioprinting system to produce human-scale tissue constructs with structural integrity. Nat Biotechnol 2016; 34: 312-9. [CrossRef]

15. Markstedt K, Mantas A, Tournier I, Martinez Ávila H, Hägg D, Gatenholm P. 3D Bioprinting Human Chondrocytes with Nanocellulose-Alginate Bioink for Cartilage Tissue Engineering Applications. Biomacromolecules 2015; 16: 1489-96. [CrossRef]

16. Murphy SV, Atala A. 3D bioprinting of tissues and organs. Nat Biotechnol 2014; 32: 773-85. [CrossRef]

17. Shanjani Y, Pan CC, Elomaa L, Yang Y. A novel bioprinting method and system for forming hybrid tissue engineering constructs. Biofabrication 2015; 7: 045008. [CrossRef]

18. Ma X, Qu X, Zhu W, Li YS, Yuan S, Zhang H, et al. Deterministically patterned biomimetic human iPSC-derived hepatic model via rapid 3D bioprinting. Proc Natl Acad Sci U S A 2016; II3: 2206-II. [CrossRef]

19. Norotte C, Marga FS, Niklason LE, Forgacs G. Scaffold-free vascular tissue engineering using bioprinting. Biomaterials 2009; 30: 59107. [CrossRef]

20. Vultur A, Schanstra T, Herlyn M. The promise of 3D skin and melanoma cell bioprinting. Melanoma Res 2016; 26: 205-6. [CrossRef]

21. Islam A, Mammadov E, Kendirci R, Aytac E, Cetiner S, Vatansever HS. In Vitro Cultivation, Characterization and Osteogenic Differentiation of Stem Cells from Human Exfoliated Deciduous Teeth on 3D Printed Polylactic Acid Scaffolds. Iran Red Crescent Med J 2017; 19: e55593. [CrossRef] 